\title{
Effect of Different Modes of Mechanical Ventilation on Chronic Obstructive Pulmonary Disease Patients with Respiratory Failure Regarding Echocardiographic Changes and Diaphragmatic Ultrasound
}

\author{
Ahmed G. EL gazzar ${ }^{\text {a }}$, Tarek S. Essawy ${ }^{\text {a }}$, Basem M. Aglan ${ }^{\text {b }}$, Emad F. Ibrahim ${ }^{\text {c }}$, Enas W. \\ Mahdy ${ }^{\mathrm{d}}$
}

${ }^{a}$ Department of chest disease, Benha faculty of medicine, Banha University, Egypt. b Department of cardio-thoracic surgery, Benha faculty of medicine, Banha University, Egypt. ${ }^{\mathrm{c}}$ Department of critical care, Benha faculty of medicine, Banha University, Egypt. d department of anesthesia and surgical intensive care, Benha faculty of medicine, Banha University, Egypt.

Correspondence to: Enas W. Mahdy, Department of anesthesia and surgical intensive care, Benha faculty of medicine, Banha University, Egypt

Email:

enaswageh@yahoo.com

Received: 26 October 2021

Accepted: 13 December 2021

\begin{abstract}
Objectives and aim:Recently, a concern has emerged with regard to the potential adverse effects of invasive mechanical ventilation on the respiratory muscles. This entity was originally termed ventilator-induced diaphragmatic dysfunction (VIDD). This study aimed to detect the impact of different modes of mechanical ventilation on diaphragmatic performance and echocardiographic parameters of COPD patients by using diaphragmatic ultrasound and ECHO.Patients and methods: The present study was carried out on 100 mechanically ventilated chronic obstructive pulmonary disease patients. Diaphragmatic ultrasonography for the assessment of diaphragmatic performance in addition to echocardiography was performed on different modes of mechanical ventilation. These patients were randomly allocated according to modes of mechanical ventilation that used into four groups, each one included 25 patients. Results:There was a highly statistically significant decrease in diaphragmatic performance when controlled mechanical ventilation (CMV) was applied only on patients, in contrary diaphragmatic performance was improved
\end{abstract} when pressure support ventilation (PSV) combined with CMV where no significant change in diaphragmatic mobility parameters occurred. And also no significant correlation was detected between echocardiographic parameters (left ventricular ejection fraction, right ventricular size, tricuspid annular plane systolic excursion, right ventricular systolic pressure) and different modes of mechanical ventilation. Conclusion: The best diaphragmatic performance was on PSV, which improved lung volumes and ventilation, and may increase the rate of success of the 
weaning process. In addition, we concluded that the echocardiographic finding was not affected by different modes of mechanical ventilation.

\section{Keywords:}

Mechanical ventilation, chronic obstructive pulmonary disease, respiratory failure, diaphragmatic ultrasound

\section{Introduction}

Chronic obstructive pulmonary disease (COPD) is a common respiratory problem that includes bronchitis and emphysema. It is becoming a major health and economic problem worldwide; in 1990, it was the sixth most common cause of death and be third most common cause at 2020 (1).

COPD is a multi-systemic disease that mainly affects and the lungs, and the muscle mass. The respiratory muscles force decreases resulting in a negative impact on the possible alteration of the ventilator and exercise capacity (2). Diaphragm is the main responsible of tidal volume in normal person

At rest; studies have shown that the impairment of diaphragmatic mobility might be associated with alterations in the principal pulmonary function parameters (3). COPD affects pulmonary blood vessels, right ventricle, and also left ventricle which lead to development of pulmonary hypertension, corpulmonale, right ventricular dysfunction, and left ventricular dysfunction too. Echocardiography provides a rapid, noninvasive portable and accurate method to evaluate the right ventricular function, right ventricular filling pressure, tricuspid regurgitation, left ventricular function and valvular function (4). Ultrasound is becoming widely used in the intensive care unit (ICU) to detect any cardiac, respiratory or diaphragmatic changes in COPD patient under mechanical ventilation $(\mathbf{5}, \mathbf{6}$, and 7). Ultrasound may be useful in giving a good idea of cardiorespiratory state at different phases of COPD and during weaning of ventilation (8).

This study aimed to assess the impact of different modes of mechanical ventilation on diaphragmatic performance and echocardiographic parameters of COPD patients by using diaphragmatic ultrasound and ECHO. 


\section{Patients and methods:}

This prospective, randomized, observerblinded and comparative clinical trial was conducted at Critical care department, Benha university hospitals from January 2020 to September 2021.

After local ethical committee approval and patient's (or his relatives) informed written consent, this study was conducted on 100 COPD male patients who fulfilled the diagnostic criteria of COPD, on invasive mechanical ventilation, their ages > 40 years, hemodynamically stable, and fully conscious.

Patients who were intubated because of surgical or medical problems other than COPD, patients with ascites, colonic distension, lung collapse, lung fibrosis, pleural effusion, any mechanical factor in the chest or abdomen interfering with diaphragmatic mobility, patients with diaphragmatic paralysis or diaphragmatic hernia, patients with chest deformities that can affect diaphragmatic mobility (i.e. kyphosis scoliosis), patients with primary cardiac diseases (i.e. myocardial infarction, cardiomyopathy, pericardial effusion, etc.), Unstable hemodynamics, comatose, neuromuscular disorder, Organ failure or electrolytes imbalance were excluded from the study.

These patients were randomly allocated according to modes of mechanical ventilation that used into four groups. An online randomization program was used to generate a number list (http://www.randomizer.org). Patient randomization numbers of were concealed in opaque envelopes which were opened by the study investigator.

In the first group (Group PCV) (25 patients), Pressure controlled ventilation (PCV) was used only as a mode of ventilation for those patients.

In the second group (Group VCV) (25 patients), Volume controlled ventilation (VCV) was used only as a mode of ventilation for those patients.

In the third group (Group PCV+PSV) (25 patients), both pressure-controlled ventilation (PCV) and pressure support ventilation (PSV) were applied alternatively on those patients.

In the fourth group (Group VCV+PSV) (25 patients), both volume-controlled ventilation (VCV) and pressure support ventilation (PSV) were applied alternatively on patients. 
At Day 1 and Day 4 of invasive mechanical ventilation, All patients were subjected to an assessment of:-

1- Full history

2- General, local examination.

3- ECG.

4- Chest radiography antero-posterior view.

5- Routine laboratory investigations such as complete blood count, Liver functions, renal profile, electrolytes.

6- Assessment of diaphragmatic mobility using baseline chest ultrasound for measurement of diaphragmatic excursion (DE) and diaphragmatic thickness (DT).

7- Transthoracic echocardiography, a subcostal four-chamber view was preferred as all the patients were emphysematous for measuring the following parameters left ventricular ejection fraction (LVEF), Rt ventricular size , Tricuspid annular plane systolic Excursion (TAPSE) and Right ventricular systolic pressure (RVSP) .

Ultrasound with double probe (LOGIQ F8 GE MEDICAL SYSTEMS CHINA CO. LTD) was used for assessment of diaphragmatic mobility and measurement of echocardiographic parameters of all patients by the same operator.

The right hemi-diaphragm excursion (DE) was measured by using a $3.5^{\circ} \mathrm{C}$ (bandwidth 2-5 MHz) convex phased array probe (a low-frequency with greater depth), M-mode was used by used it during inspiration and expiration and then calculate the distance between the dome and bottom of the diaphragmatic line in freeze mode. M-mode had more advantage than B-mode as it more accurate and easier for interpretation and less time consuming than B-mode.

Diaphragmatic thickness (DT) was measured by an M12L linear array probe (bandwidth: 5-13 MHz) that placed at the anterior axillary line at intercostal space number 7 and number 8 , giving an image that giving a complete picture about the liver and the lung and a zone of apposition between them using the B mode. Both of the pleural lining and the peritoneal lining appeared clearly as two approximately parallel echogenic lines. The space between them resembles diaphragmatic thickness.

Left ventricular ejection fraction (LVEF) was measured by M-mode, 2-D techniques in the left parasternal short-axis and longaxis views. Computer software on the 
ECHO machine was used to assess quantitative left ventricular function.

Right ventricular size was assessed by measurement of the right internal mid cavity dimension in the apical four-view.

Tricuspid annular plane systolic excursion (TAPSE) was measured by putting the Mmode cursor on the lateral tricuspid annulus, and the maximum plane systolic excursion of the lateral annulus was calculated.

Right ventricular systolic pressure (RVSP) was calculated on the basis of the modified Bernoulli equation and was considered to be equal to the sPAP, RVSP=trans tricuspid pressure gradient + right atrial pressure ,Trans tricuspid gradient is $4 \mathrm{v} 2$ ( $\mathrm{v}=$ peak velocity of tricuspid regurgitation, $\mathrm{m} / \mathrm{s}$ ), Right atrial pressure was estimated from the end- expiratory diameter of the inferior vena cava.

\section{Statistical analysis:-}

Analysis of data was performed by using SPSS (version 16; SPSS Inc., Chicago, Illinois, USA). Quantitative data were presented as mean and SD and were analyzed using a one-way analysis of variance test. Significant ANOVA test was further analyzed by post-hoc analysis (Bonferroni correction). Qualitative data were presented as numbers and percentages and were analyzed using the $\chi^{2}$ and Fisher exact tests. A $P$-value less than 0.05 were considered significant, whereas a $P$-value less than 0.01 were considered highly significant.

Sample size was calculated according to a pilot study for the $1^{\text {st }}$ five patients in each group. Assuming that the power of the study was $80 \%$ and alpha error was 0.05 to detect a clinically significant difference between the measurement of diaphragmatic excursion (primary outcome) at $1^{\text {st }}$ and $4^{\text {th }}$ days. The calculated effect size was 0.548 . Twenty two patients were calculated in each group. We considered 25 patients per group to overcome the dropout.

\section{Results:}

Study Involved 100 men patients, divided in 4 groups according to mode of mechanical ventilation that used, each group involved 25 patients, ranging in age between 40 to 78 years with no significant value regarding age and patient's weight ranging between 70 to $89 \mathrm{KG}$ with no significant value regarding weight (table 1). 
Table 1- Detailed Demographic characteristics in 4 groups

\begin{tabular}{llllll}
\hline & Group PCV & Group & Group & Group & $p$-value \\
& & CVV & PCV+PSV & VCV+PSV & \\
\hline Age(years) & $57.16 \pm 10.43$ & $56.84 \pm 10.51$ & $56.24 \pm 9.75$ & $57.12 \pm 9.53$ & 0.98 \\
Weight(kg) & $77.88 \pm 4.37$ & $81.04 \pm 4.81$ & $78.96 \pm 4.98$ & $80.68 \pm 4.00$ & 0.054 \\
\hline
\end{tabular}

Diaphragmatic excursion (DE) was measured for all patient in four groups at $1^{\text {st }}$ day and $4^{\text {th }}$ day of MV on different modes, in both first group (PCV) and second group (VCV) there was significant decrease in DE with use of PCV alone or VCV alone but on the contrary in both third and fourth group there was no significant changes in DE when PCV or VCV mode combined with PSV mode (fig 1).

And also results of diaphragmatic thickness (DT) measurement for all patient in four groups at $1^{\text {st }}$ day and $4^{\text {th }}$ day of MV on different modes, reveals that there is significant value in both first and second groups as there is decrease in DT with use of PCV and VCV alone but no significant changes occur in DT when PCV or VCV mode combined with PSV mode (fig. 2).

Regarding Echocardiographic parameters in form LVEF, RV size, TAPSE and RVSP were measured at $1^{\text {st }}$ day and $4^{\text {th }}$ day of MV at different modes, all four Echocardiographic parameters results show no significant change in all groups of different modes of $\mathrm{MV}$ in both $1^{\text {st }}$ and $4^{\text {th }}$ day.(fig 3,4,5 and 6).

\section{DE}

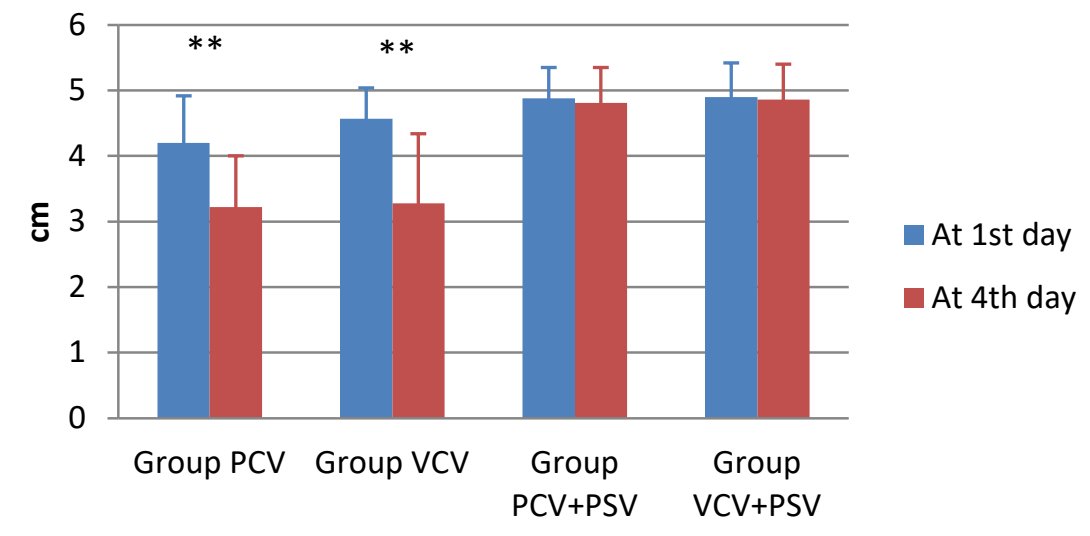

Figure 1: Diaphragmatic Excursion Measurements in 4 groups at $1^{\text {st }}$ and $4^{\text {th }}$ day of MV 
Benha medical journal, vol. 39. issue 1, 2022

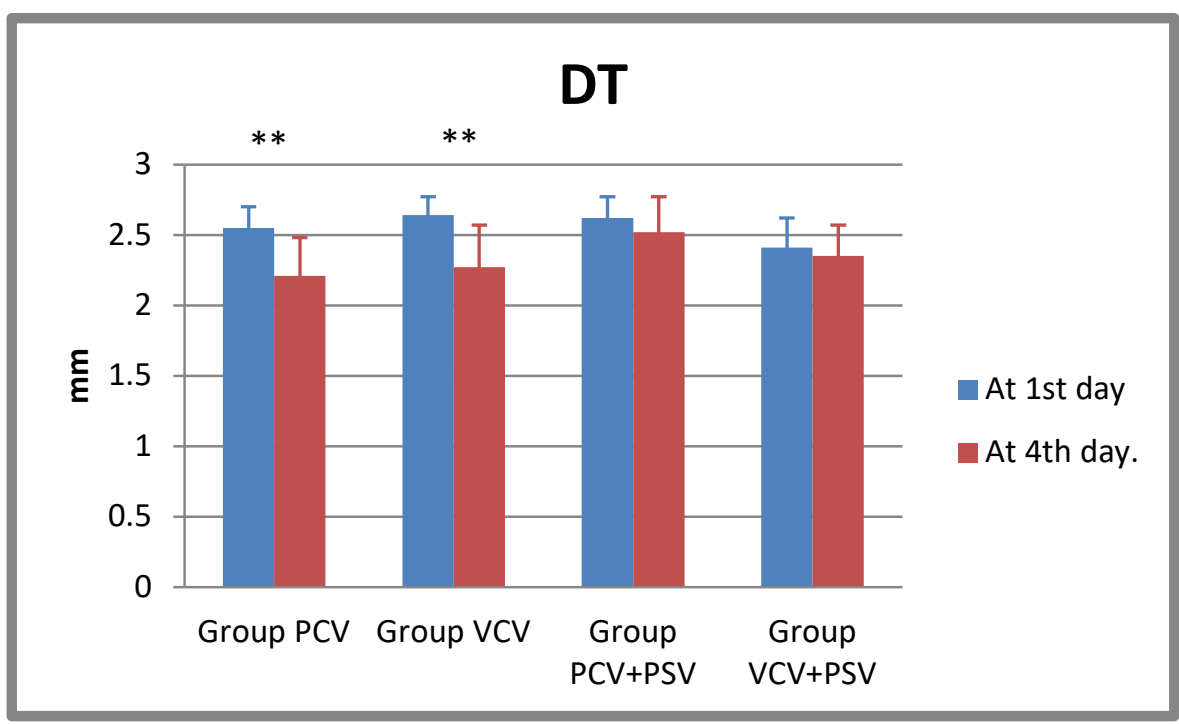

Figure 2: Diaphragmatic thickness Measurements in 4 groups at $1^{\text {st }}$ and $4^{\text {th }}$ day of MV.

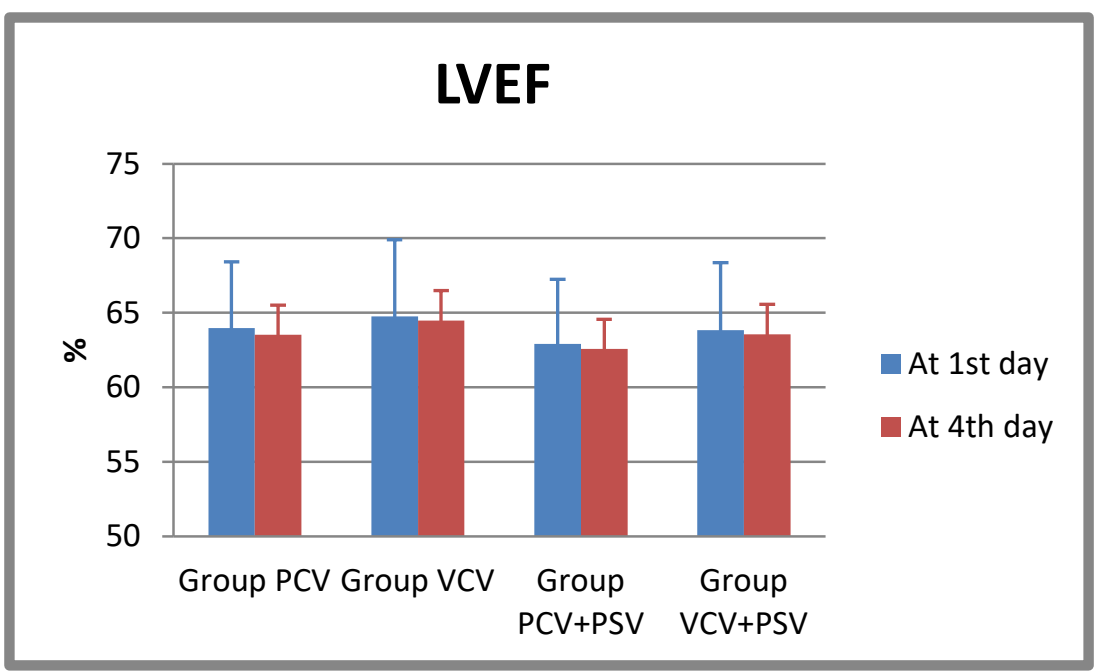

Figure 3:- LVEF Measurements in 4 groups at $1^{\text {st }}$ and $4^{\text {th }}$ day of MV 


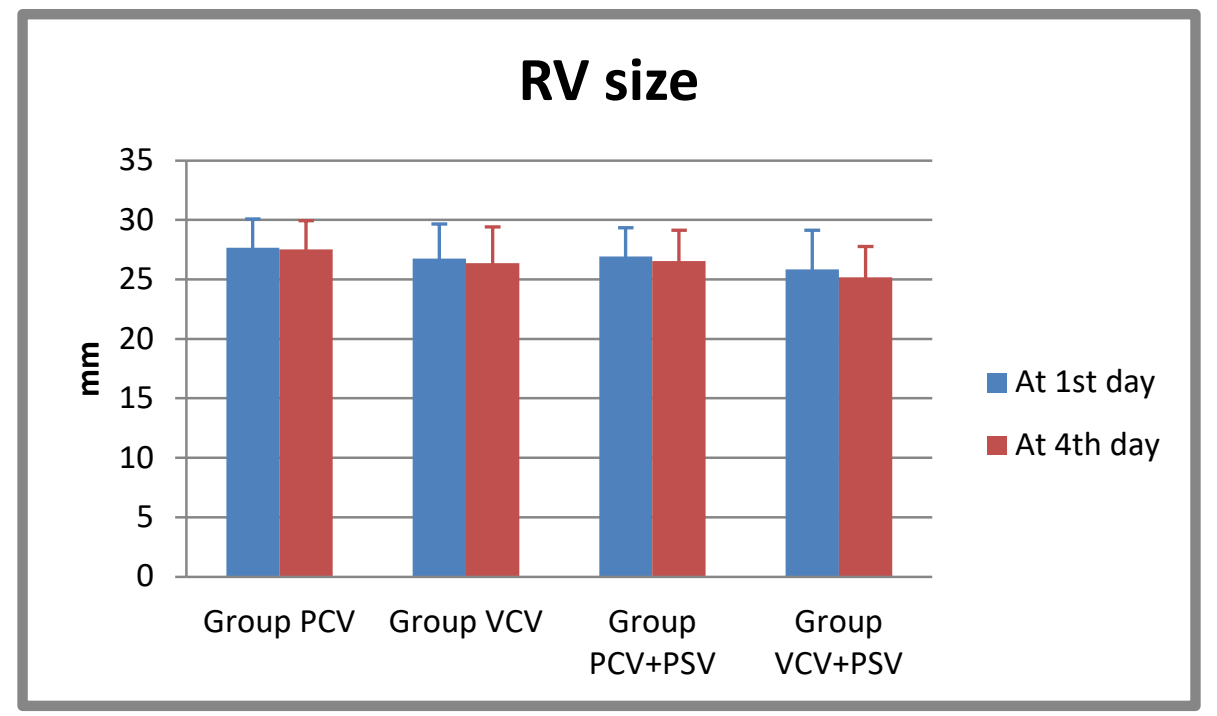

Figure 4:- RV Size Measurements in 4 groups at $1^{\text {st }}$ and $4^{\text {th }}$ day of MV

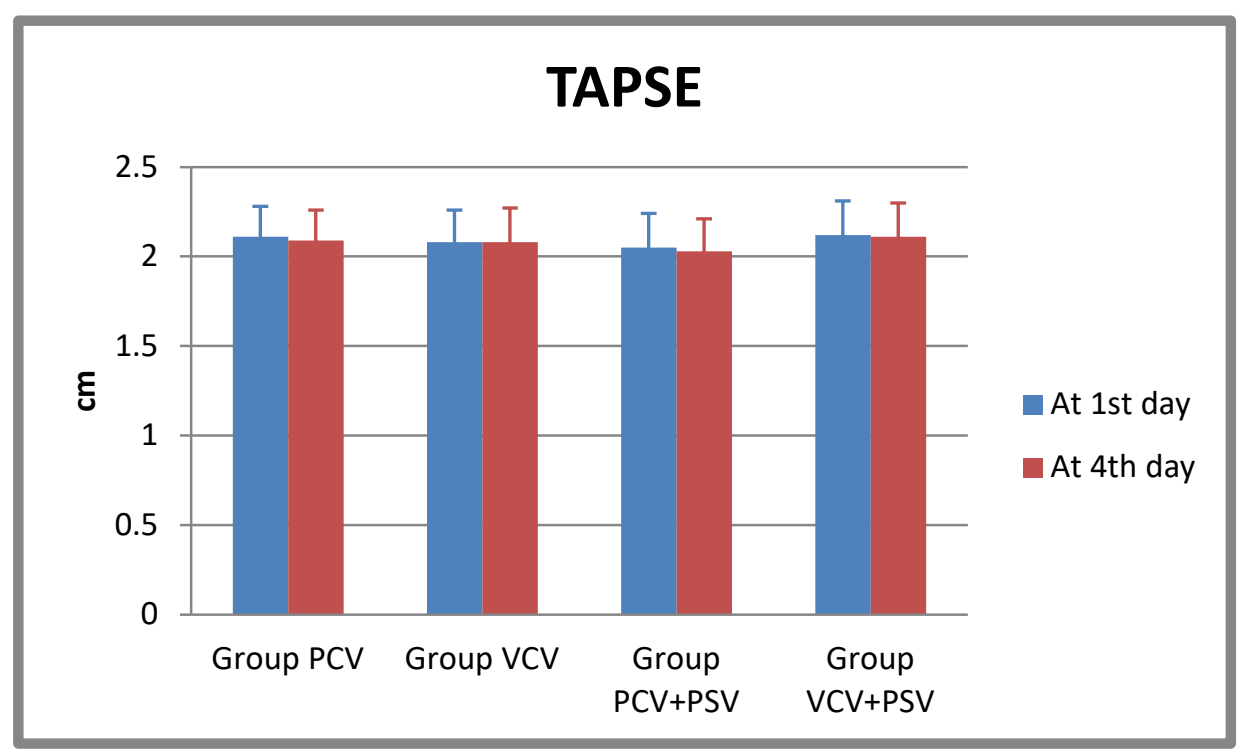

Figure 5:- TAPSE Measurements in 4 groups at $1^{\text {st }}$ and $4^{\text {th }}$ day of MV 


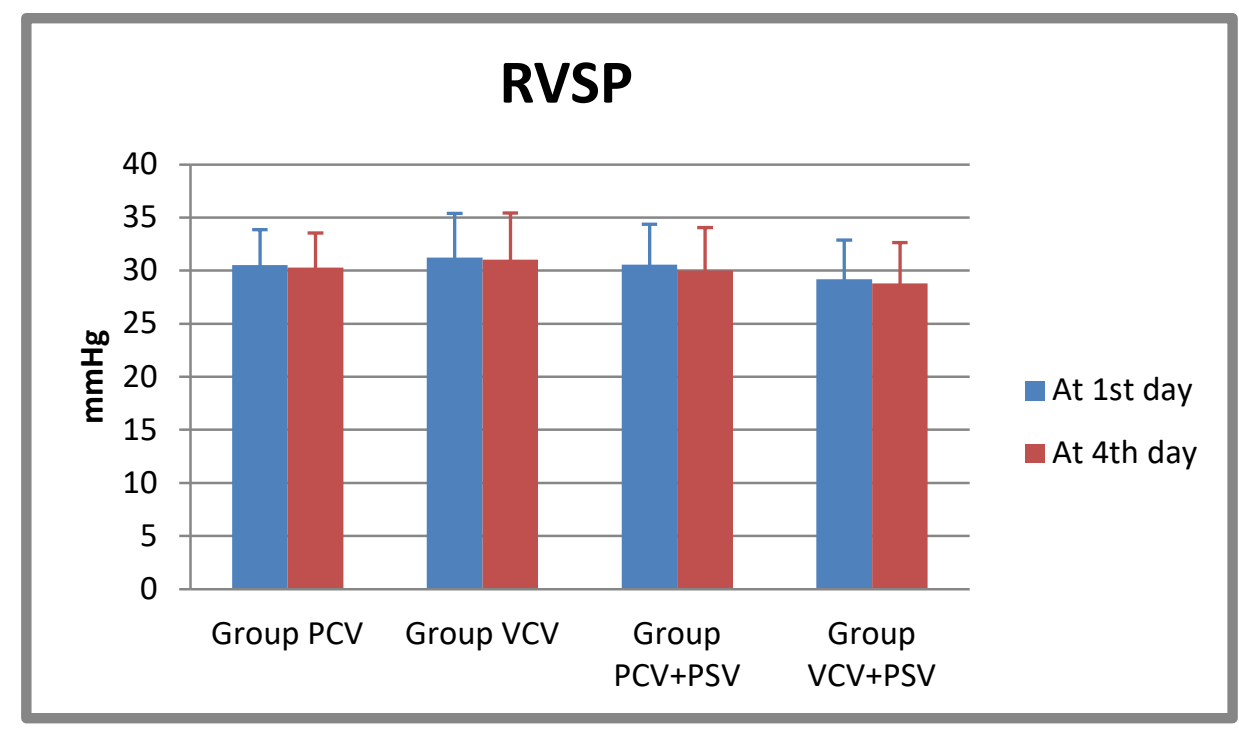

Figure 6: RVSP Measurements in 4 groups at $1^{\text {st }}$ and $4^{\text {th }}$ day of MV

\section{Discussion}

Ventilating a COPD patient is often difficult because the disease may not have a reversible component. Further, quantification and management of dynamic hyperinflation (DH) at bedside is very difficult (9) so the choice of method and ventilator parameters to be used must be specific for each patient's disease severity. One of the complications that should be avoided is dynamic over-inflation and consequent auto-PEEP, which has ventilatory and hemodynamic repercussions (10). In patients on controlled mechanical ventilation, there is serious diaphragmatic dysfunction and atrophy and, for this attempts should be made for the patient to early initiate with spontaneous breathings, adjusting the work of breathing (11).The diaphragm is a fundamental respiratory muscle whose dysfunction may be very common in patients undergoing mechanical ventilation. Diaphragmatic dysfunction is associated with prolonged mechanical ventilation and weaning failure (12). U/S is widely available inside the ICU that provide direct, bed side, rapid visualization and assessment of the diaphragmatic mobility and diaphragmatic function as the main respiratory muscle which may be used as indicator for the weaning outcome (13).

In this study we assessed the impact of different modes of mechanical ventilation on 
diaphragmatic performance and echocardiographic parameters of COPD patients by using diaphragmatic ultrasound and ECHO.

This study showed that there was statistically high significant decrease in both diaphragmatic excursion and diaphragmatic thickness when controlled ventilation mode as pressure-controlled ventilation or Volume controlled ventilation used alone, in contrary no significant change in both those diaphragmatic parameters with use controlled ventilation and pressure support ventilation alternatively. And also it showed that there was an insignificant correlation between echocardiography as regard left ventricular ejection fraction, right ventricular size, tricuspid annular plane systolic excursion, right ventricular systolic pressure and different modes of mechanical ventilation.

This was agreed with (14)study that involves 107 patients were enrolled shortly after initiating ventilation along with 10 non ventilated patients in intensive care unit (control subjects). Diaphragm thickness and contractile activity (quantified by the inspiratory thickening fraction) were daily measured by ultrasound. Results found that during the first week of ventilation, decrease of diaphragm thickness in about $10 \%$ in 47 (44\%), and unchanged in 47 (44\%), and increased by more than $10 \%$ in $13(12 \%)$. On the other hand, thickness did not vary over time following extubation or in non-ventilated patients

In the study which was was conducted from December 2018 to February 2019 at Cipto Mangun kusumo National Hospital, thirty ventilated critically ill patients in the ICU were included (15). Baseline demographic data were collected. Baseline end-expiratory diaphragm thickness was measured within one hour after intiating mechanical ventilation and repeated every 24 hours for four days, and recorded of mortality and duration of mechanical ventilation results show no significant differences in the following data as baseline diaphragm thickness according to gender, body mass index and modified Rankin Score. The subjects were divided into two groups' duration of mechanical ventilation less than seven days and duration of ventilation of seven days or more, and showed that The mean baseline diaphragm thickness was 2.11 $+0.15 \mathrm{~mm}$. and also decrease of diaphragm muscle thickness that occurred in about 24 hours. . It was found that rapid decrease in diaphragm muscle thickness corresponded 
with longer duration of mechanical ventilation those worse outcomes

It was revealed that the largest decrease in thickness occurred during the first 72 hours of MV. Diaphragm atrophy occurs quickly in mechanically ventilated patients and can accurately be monitored using ultrasound (16). A study found that decreased diaphragm and intercostal muscle thickness that were measured on days $1,3,5$, and 7 with ultrasonography were frequently seen in mechanical ventilated patient. They were associated with prolonged mechanical ventilation and increase length of ICU stays (17). Whereas in another study (18), it was found that low baseline diaphragm muscle mass occurred in prolonged mechanical ventilation and associated with a higher risk of in-hospital death.

On the contrary a study showed that patients admitted to the ICU after major elective surgery who met criteria for a spontaneous breathing trial with pressure support ventilation, found that there was no statistically significant change in diaphragmatic excursion with increasing ventilator support. This difference may be due to difference in selection of the patients where patients admitted to the ICU after major elective surgery who met criteria for a spontaneous breathing trial with pressure support ventilation were enrolled. Patients with airflow obstruction were excluded. These patients in pain and this may interfere with diaphragmatic mobility who excluded from our study (19).

This was in agreement with the study which assessed twenty-four adult mechanical ventilated patients for more than $48 \mathrm{~h}$ and considered ready for weaning. Cardiorespiratory variables, oxygenation, electro-cardiogram and Doppler echocardiogram findings were analyzed at baseline and after 30 minutes in pressure support ventilation and T-tube, found that no echocardiographic differences were observed between pressure support ventilation and T-tube (20).

This was in the contrary to that study which found that spontaneous breathing trial (SBT) induced changes in central hemodynamics and helps in identifying patients at high risk of cardiac-related weaning failure when documenting a depressed left ventricular ejection fraction (LVEF). This can be explained by different groups of patients as all patients mechanically ventilated for more than 48 hours and fulfilled weaning criteria including COPD patients, patients with acute respiratory failure, patients with severe 
sepsis and septic shock, cardiogenic shock and patients with neurological disorders and stroke were enrolled in their study, also SBT was performed over a 30 minute period using T-piece (21)

This was highly in agreement with the study which proved that spontaneous breathing (SB) intensity is negatively associated with the development of VIDD. Maintenance of SB at an intensity of $60 \%-80 \%$ may effectively prevent the occurrence of VIDD (22).

\section{Conclusion:}

This study provided the impact of different modes of mechanical ventilation on diaphragmatic mobility and echocardiographic parameters and revealed that controlled mechanical ventilation promotes diaphragmatic weakness, but spontaneous mode of ventilation with pressure support improve diaphragmatic performance by improving lung volumes and ventilation as observed and also concluded that no echocardiographic parameters changes occurred on different modes of mechanical ventilation.

\section{References:}

1. García Vicente E, Sandoval Almengor JC, Díaz Caballero LA, Salgado Campo JC (2011): Invasive mechanical ventilation in COPD and asthma. Med Intensiva 35:288-98. [PubMed] [Google Scholar].

\section{2-AlexandruSomesan ,Cristian Oancea, Ovidiu Fira-Mladinescu, AlexandruCrisan, EmanuelaTudorache (2014) : Diaphragmatic muscle ultrasound in COPD patients .European Respiratory Journal .44. 802.}

3-Wellington Pereira, Dos Santos Yamaguti, Elaine Paulin, Simone Shibao, Maria Cristina Chammas (2008): Air trapping: The major factor limiting diaphragm mobility in chronic obstructive pulmonary disease patients.Respirology.13.138-144.

4. Daniels LB, Krum men DE, Blanchard DG (2004): Echocardiography in pulmonary vascular disease. Cardio Clin ;22:383-99. [PubMed] [Google Scholar].

5. Caille V, Amiel JB, Charron C, Belliard G, Vieillard-Baron A, Vignon $P$ (2010): Echocardiography: a help in the weaning process. Crit Care ;14(3):R120. DOI: 10.1186/cc9076. [PMC free article] [PubMed] [CrossRef] [Google Scholar].

6. Soummer A, Perbet S, Brisson H, Arbelot C, Constantin JM, Lu Q (2012): Ultrasound assessment of lung aeration loss during a successful weaning trial predicts postextubation distress*. Crit Care Med.;40(7):2064-2072. [PubMed] [CrossRef] [Google Scholar].

7. Kim WY, Suh HJ, Hong SB, Koh Y, Lim CM (2011) : Diaphragm dysfunction assessed by ultrasonography: influence on weaning from mechanical ventilation. Critical Care Med.;39(12):2627-2630. [PubMed] [CrossRef] [Google Scholar].

8. Mayo P, Volpicelli G, Lerolle N, Schreiber A, Doelken P, Vieillard-Baron A (2016): Ultrasonography evaluation during the weaning process: the heart, the diaphragm, the pleura and the lung. Intensive Care Med; 42(7):1107-1117. [PubMed] [CrossRef] [Google Scholar].

9-Qaseem A, Wilt TJ, Weinberger SE, Hanania NA, Criner G, van der Molen T.(2011): Diagnosis 
and management of stable chronic obstructive pulmonary disease: A clinical practice guideline update from the American College of Physicians, American College of Chest Physicians, American Thoracic Society, and European Respiratory Society. Ann Intern Med; 155:179-9.

10-Jezler S, Holanda M, José A (2007): Consenso Brasileiro de Ventilação Mecânica. Ventilação mecânica na doença pulmonar obstrutiva crônica (DPOC) descompensada. J Bras Pneumol. 2007; 33(1):111-8.

11-Vivier E, Mekontso Dessap A, Dimassi S, Vargas F, Lyazidi A, Thille AW, et al. (2012): Diaphragm ultrasonography to estimate the work of breathing during non-invasive ventilation. Intensive Care Med; 38:796-803.

12- Giovanni Ferrari, Giovanna De Filippi, Fabrizio Elia, Francesco Panero, Giovanni Volpicelli, Franco Aprà (2014): Diaphragm ultrasound as a new index of discontinuation from mechanical ventilation. Critical Ultrasound Journal, 6:8-9.

13-Osman A, Hashim R (2017): Diaphragmatic and lung ultrasound application as new predictive indices for the weaning process in ICU patients. The Egyptian Journal of Radiology and Nuclear Medicine, 48:61-66.

14-Niall D Ferguson, Ewan C Goligher, Eddy Fan, Margaret S Herridge, Alistair Murray, Stefanie Vorona, Debbie Brace (2015): evolution of diaphragm thickness during mechanical ventilation. Impact of inspiratory effort, American journal of respiratory and critical care medicine 192 (9), 10801088

15-Bram Kilapong, Dita Aditianingsih, Rudyanto Sedona, Adhrie Sugiarto, Thariqah Salamah (2021): Diaphragm muscle thinning in mechanically ventilated critically ill patients JPMA. The Journal of the Pakistan Medical Association Volume 712: 2.
16-Philippe G. Jorens, Tom Schepens, Walter Verbrugghe, (2015): The course of diaphragm atrophy in ventilated patients assessed with ultrasound. Critical Care volume, 19: 422.

17-Jun Oto, Nobuto Nakanishi, Yoshitoyo Ueno, Emiko Nakataki, Taiga Itagaki and Masaji Nishimura (2019):Change in diaphragm and intercostal muscle thickness in mechanically ventilated patients: a Journal of Intensive care 18:3.

18-Michael C. Sklar, Martin Dres, Eddy Fan (2020): Association of Low Baseline Diaphragm Muscle Mass With Prolonged Mechanical Ventilation and Mortality Among Critically Ill Adults JAMA network open ;3(2).

19-Umbrello M, Paolo F, Daniela L, Andrea G, Ilaria P, Angelo P, et al. (2015): Diaphragm ultrasound as indicator of respiratory effort in critically ill patients undergoing assisted mechanical ventilation: a pilot clinical study, Critical Care 19:161.

20-Lucille M, Silvia R, Janete S, Deise M,,and Alexandre Antonio N.(2011): Echocardiographic evaluation during weaning from mechanical ventilation .Clinics (Sao Paulo). 2011 Jan; 66(1): $107-111$.

21-Caille V, Arniel JB, Charron C, Belliard G, Vieillard- Baron A, Vignon P.(2010): Echocardiography: a help in the weaning process. Crit Care.; 14:120, doi: 10.1186/cc9076.

22-Luo Z, Han S, Sun W, Wang Y, Liu S, Yang L (2020): Maintenance of spontaneous breathing at an intensity of $60 \%-80 \%$ may effectively prevent mechanical ventilation-induced diaphragmatic dysfunction. PLoS ONE 15: (3).

To cite this article: Ahmed G. EL gazzar, Tarek S. Essawy, Basem M. Aglan, Emad F. Ibrahim, . Enas W. Mahdy. Effect of Different Modes of Mechanical Ventilation on Chronic Obstructive Pulmonary Disease Patients with Respiratory Failure Regarding Echocardiographic Changes and Diaphragmatic Ultrasound. BMFJ 2022;39 (1): 62-74. DOI: 10.21608/bmfj.2021.102965.1508 